\title{
Expose the Media Package on "Beti Bachao Beti Padhao" Scheme among Rural People in Varanasi District of Uttar Pradesh
}

\author{
Ambay Singh ${ }^{1 *}$, Richa Kumari ${ }^{2}$, Pushpa Kumari $^{3}$ and Kumari Madhu ${ }^{2}$ \\ ${ }^{1}$ Home Science Extension \& Communication (HSEC), Banaras Hindu University, India \\ ${ }^{2}$ Home Science Extension \& Communication Management (HSECM), \\ Dr. Rajendra Prasad Central Agricultural University, Pusa, Samastipur, Bihar, India \\ ${ }^{3}$ Department of Home Science, Banaras Hindu University, India \\ *Corresponding author
}

\begin{abstract}
A B S T R A C T
Education for women is the best way to improve the health, nutrition and economic status of a household that constitute a micro unit of a nation economy. In this context, it can be argued that lack of women education can be an impediment to the country's economic development. In India, women achieve far less education that of men. As per the Census Report 2011, the literacy rate of women is 65.46 per cent and that of men is 82.14 per cent. The Union Government has expanded "Beti Bachao Beti Padhao" (BBBP) programme from 161 districts to all 640 districts of the country. As per data available in Health Management Information System (HMIS), there has been improvement in sex ratio at birth (SRB). The SRB which was 918 in 2014-15 has improved to 926 in 2016-17 as per HMIS data. This is the miserable condition of the daughters in some parts of the country where the girls are not treated equal to boys, not allowed to go to the schools beyond primary classes, deprived of all the facilities which their brothers enjoy with extreme liberty and in some cases the girls are not allowed to take birth and they get killed in the womb of their mothers. "Beti Bachao Beti Padhao" Scheme is a central government programme. "Beti Bachao Beti Padhao" is an effective campaign to save the girl child and educate the girl child all over the India. It is a scheme run by the Government of India with the aim of spreading awareness as well as improving the efficient of welfare services for the girls of India
\end{abstract}

\section{Introduction}

"You educate a man; you educate a man. You educate a woman; you educate a generation."

-Brigham Young
Education for women is the best way to improve the health, nutrition and economic status of a household that constitute a micro unit of a nation economy. In this context, it can be argued that lack of women education can be an impediment to the country's economic development. 
In India, women achieve far less education that of men. As per the Census Report 2011, the literacy rate of women is 65.46 per cent and that of men is 82.14 per cent. The Union Government has expanded Beti Bachao Beti Padhao (BBBP) Programme from 161 districts to all 640 districts of the country. As per data available in Health Management Information System (HMIS), there has been improvement in Sex Ratio at Birth (SRB).

The SRB which was 918 in 2014-15 has improved to 926 in 2016-17 as per HMIS data. The successful implementation of BBBP Programme in states and districts has led government to decide to go Pan-India and expand the programme to all districts. This is the miserable condition of the daughters in some parts of the country where the girls are not treated equal to boys, not allowed to go to the schools beyond primary classes, deprived of all the facilities which their brothers enjoy with extreme liberty and in some cases the girls are not allowed to take birth and they get killed in the womb of their mothers. The female crowds in rural area are deprived of minimum facilities of enlightenment and education.

Gender empowerment is conceived as a process by which women can overcome many of the hurdles that they face such as education, work status, employment opportunity, healthcare, social security, position in decision making by virtue of their gender. Verma (2003) observed that after imparting the knowledge through various visual/printed materials such as posters, charts, leaflets and booklets, a significant gain in knowledge was recorded. Prathap and Ponnusamy (2006) suggested that print media that were placed second too have proven to be effective in influencing the knowledge gain of rural women. There is a general feeling that print media are being under-utilized due to the low literacy levels prevailing in India. On the contrary, statistics show that rural literacy has been showing a steady progress over the years. "Beti Bachao Beti Padhao" Scheme is a central government programme run by the Government of India with the aim of spreading awareness as well as improving the efficient of welfare services for the girls of India. It is an effective campaign to save the girl child and educate the girl child all over the India.

The Prime Minister of India, Narendra Modi, has started a "Sukanya Samriddhi Yojana" (launched on 21st of January in 2015) under the Beti Bachao Beti Padhao scheme. "Sukanya Samriddhi Yojana" was launched to support this scheme as well as make it successful by meeting the essential expenses of the girl child such as health, higher education and marriage. This scheme is a good start for the girl child lives as it involves some effective efforts of the Government of India.

It is a best scheme ever as it reduces the tension of parents as well as will save the lives of present and future born girls through this small investment on annual basis. This project was started with the initial amount of Rs. 100 crore. It is also reported that Ministry of Home Affairs spent around Rs 150 crore over this scheme to assure women safety in large cities of India. This scheme has been planned and launched to reduce the level and effect of some dangerous social issues related to the girl child. The scheme is regarding girl's safety, protection and better education in the future without much load on the parents. The nationwide campaign is initiated to increase the awareness among people for saving and educating the girl child. It has aimed to ensure that girls are born, well nurtured and educated without being discriminated. It is to empower almost other half population of the country by giving them equal rights. 
This campaign requires National, State, District and community level interventions of people and different stakeholders for accelerated impact over CSR issue. This campaign has aimed to improve the condition of girls as well as make them independent both socially and financially in the future through proper and higher education. It is positive result generating awareness programme in order to improve the efficiency of welfare service for women. The objective is to develop and expose the media package on "Beti Bachao Beti Padhao" to rural people.

\section{Materials and Methods}

The present study was carried out in Varanasi district of Uttar Pradesh state purposively because this district was close to the purpose of the study and in this area people were not aware about scheme BBBP. From Varanasi district Kashi Vidyapeeth block selected for the study. There were 80 respondents were selected from two villages namely Tarapur Tikari and Karaundi of Varanasi district randomly. Statistical tools used for study were frequency and percentage (Fig. 1 and Table $1)$.

Table.1 Indian Districts under "Beti Bachao Beti Padhao" Program

\begin{tabular}{|c|c|c|c|c|}
\hline Sl. No. & Name of State / UT & Districts & Census 2001 & Census 2011 \\
\hline & INDIA & & 927 & 918 \\
\hline 1 & \multirow{4}{*}{ Gujarat (4) } & Anand & 849 & 884 \\
\hline 2 & & Amreli & 892 & 886 \\
\hline 3 & & Patan & 865 & 890 \\
\hline 4 & & Bhavnagar & 881 & 891 \\
\hline 5 & \multirow[t]{8}{*}{ Haryana (8) } & Gurgaon & 807 & 830 \\
\hline 6 & & Jind & 818 & 838 \\
\hline 7 & & Faridabad & 847 & 843 \\
\hline 8 & & Hisar & 832 & 851 \\
\hline 9 & & Fatehabad & 828 & 854 \\
\hline 10 & & Sirsa & 817 & 862 \\
\hline 11 & & Panchkula & 829 & 863 \\
\hline 12 & & Palwal & 854 & 866 \\
\hline 13 & \multirow[t]{2}{*}{ Himachal Pradesh (2) } & Kangra & 836 & 876 \\
\hline 14 & & Hamirpur & 850 & 887 \\
\hline 15 & \multirow[t]{10}{*}{ Jammu \& Kashmir (10) } & Samba & 798 & 779 \\
\hline 16 & & Baramula & 961 & 863 \\
\hline 17 & & Ganderbal & 1014 & 863 \\
\hline 18 & & Rajouri & 905 & 865 \\
\hline 19 & & Srinagar & 983 & 865 \\
\hline 20 & & Shupiyan & 1011 & 878 \\
\hline 21 & & Kupwara & 1021 & 879 \\
\hline 22 & & Kulgam & 1003 & 885 \\
\hline 23 & & Udhampur & 912 & 886 \\
\hline 24 & & Bandipore & 967 & 892 \\
\hline
\end{tabular}


Int.J.Curr.Microbiol.App.Sci (2020) 9(4): 1169-1174

\begin{tabular}{|c|c|c|c|c|}
\hline 25 & \multirow[t]{2}{*}{ Madhya Pradesh (2) } & Rewa & 926 & 885 \\
\hline 26 & & Tikamgarh & 916 & 892 \\
\hline 27 & \multirow[t]{6}{*}{ Maharastra (6) } & Hingoli & 927 & 882 \\
\hline 28 & & Solapur & 895 & 883 \\
\hline 29 & & Pune & 902 & 883 \\
\hline 30 & & Parbhani & 923 & 884 \\
\hline 31 & & Nashik & 920 & 890 \\
\hline 32 & & Latur & 918 & 889 \\
\hline 33 & \multirow[t]{2}{*}{ NCT of Delhi } & North East & 875 & 880 \\
\hline 34 & & South & 888 & 885 \\
\hline 35 & \multirow[t]{9}{*}{ Punjab } & Faridkot & 812 & 851 \\
\hline 36 & & Bathinda & 785 & 854 \\
\hline 37 & & Ludhiana & 817 & 860 \\
\hline 38 & & Moga & 818 & 860 \\
\hline 39 & & Rupnagar & 799 & 863 \\
\hline 40 & & Hoshiarpur & 812 & 865 \\
\hline 41 & & Kapurthala & 785 & 871 \\
\hline 42 & & Jalandhar & 806 & 874 \\
\hline 43 & & $\begin{array}{c}\text { Shahid Bhagat Singh } \\
\text { Nagar }\end{array}$ & 808 & 885 \\
\hline 44 & \multirow[t]{4}{*}{ Rajasthan } & Jaisalmer & 869 & 874 \\
\hline 45 & & Hanumangarh & 872 & 878 \\
\hline 46 & & Jodhpur & 920 & 891 \\
\hline 47 & & Tonk & 927 & 892 \\
\hline 48 & \multirow[t]{11}{*}{ Uttar Pradesh (11) } & Etawah & 895 & 875 \\
\hline 49 & & Aligarh & 886 & 877 \\
\hline 50 & & Etah & 880 & 879 \\
\hline 51 & & Firozabad & 887 & 881 \\
\hline 52 & & Jalaun & 889 & 881 \\
\hline 53 & & Bijnor & 905 & 883 \\
\hline 54 & & Mainpuri & 892 & 884 \\
\hline 55 & & Hamirpur & 904 & 886 \\
\hline 56 & & Saharanpur & 872 & 887 \\
\hline 57 & & Farrukhabad & 897 & 889 \\
\hline 58 & & Mahoba & 900 & 892 \\
\hline 59 & \multirow[t]{3}{*}{ Uttarakhand (3) } & Hardwar & 862 & 877 \\
\hline 60 & & Dehradun & 894 & 889 \\
\hline 61 & & Chamoli & 935 & 889 \\
\hline
\end{tabular}

The Ministry of Women and Child Development has expanded "Beti Bachao Beti Padhao" scheme in additional 61 district (covering 11 states). 


\section{Results and Discussion}

Table 2 revealed that 32 respondents means only 40 per cent were using newspaper and magazine for getting information about BBBP scheme and 48 respondents means 60 per cent using radio and television for getting information about BBBP scheme. None of the respondents were using computer, internet, any campaign for getting information about Beti Bachao Beti Padhao scheme and its benefits.

Finally the study concluded that "Beti Bachao Beti Padhao" mission emphasizes on safeguarding and strengthening the rights of women. People are becoming more sensitized and several girls of India are bringing accolades to the nation and becoming popular on International level. Thus, people should stop discriminating between the girl and the boy child and support both the genders equally. This programme is to remove the social biases favoring the male child in society as well as improving the status of girl child through safety and education. This scheme is not a medicine curing a disease however it is a supportive plan. It can be successful only when it will be supported by us. There is need to change the attitude and mindset (especially parents) towards the girl child forever so that she too can get the same opportunity after her birth like safety, health care, education, etc. In this way, a girl child can be an independent entity and not a burden over her parents. The various strategies needed to be followed for the effectiveness of this scheme. It needs social mobilization and fast communication regarding equal value of the girl child and her education. There is need of awareness, appreciation and support by the end of all citizens especially youth and women groups for this social change.

Table.2 Distribution of respondents according to information gained about "Beti Bachao Beti Padhao" Scheme through different media exposure

\begin{tabular}{|c|c|c|c|}
\hline Sl. No. & Source of Information & Frequency & Percentage \\
\hline $\mathbf{1}$ & Newspaper/Magazine & 32 & 40 \\
\hline $\mathbf{2}$ & Radio/Television & 48 & 60 \\
\hline $\mathbf{3}$ & Computer/Internet & 0 & 0 \\
\hline $\mathbf{4}$ & Campaign & 0 & 0 \\
\hline $\mathbf{5}$ & Not known & 0 & 0 \\
\hline & Total & $\mathbf{8 0}$ & $\mathbf{1 0 0}$ \\
\hline
\end{tabular}




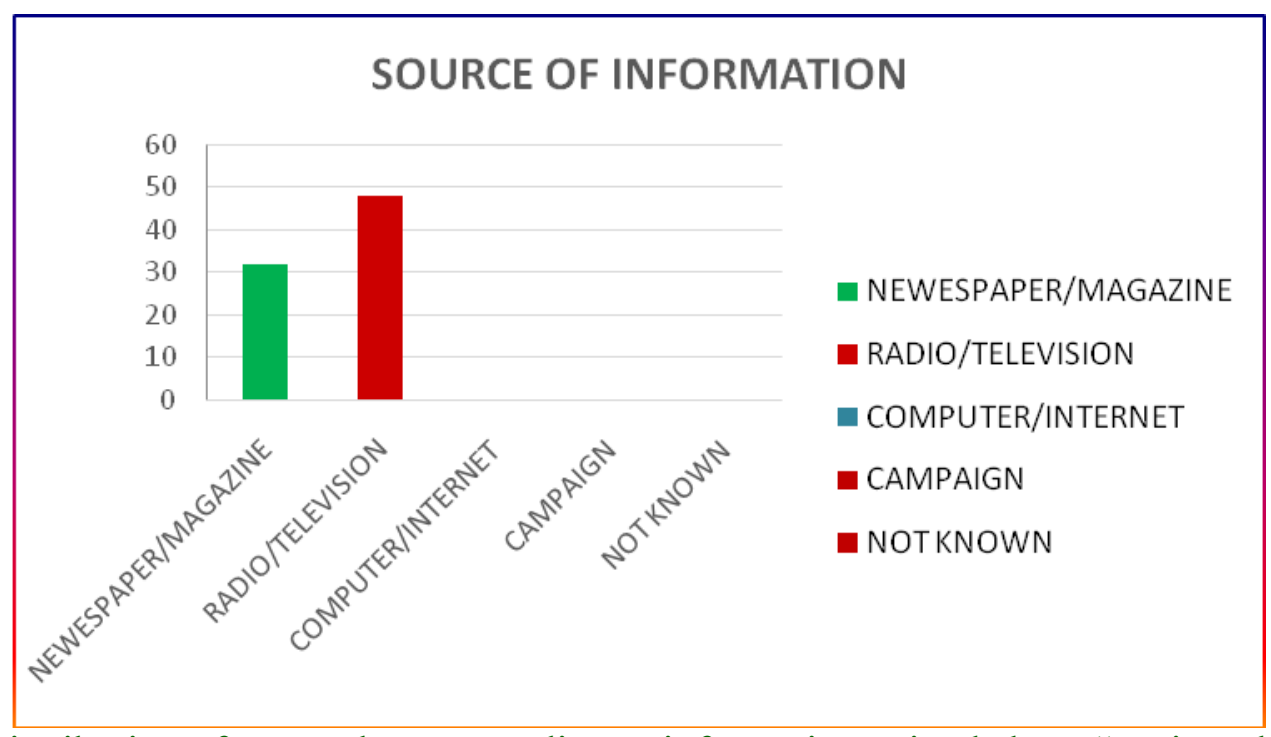

Fig.1 Distribution of respondents according to information gained about "Beti Bachao Beti Padhao" Scheme through different media exposure

\section{References}

Beti Bachao Beti Padhao- Vikaspedia 2016. Prathap, D.P. and Ponnusamy K.A. (2006), effectiveness of four mass media channels on the knowledge gain of rural women . spiring 13(1): 73-81.

Verma, S. (2003). Food consumption Pattern and Nutritional status of preschool children Yamunanagar district. M. Sc. Thesis, CCS Haryana Agricultural, University, Hissar, Haryana.

\section{How to cite this article:}

Ambay Singh, Richa Kumari, Pushpa Kumari and Kumari Madhu. 2020. Expose the Media Package on "Beti Bachao Beti Padhao" Scheme among Rural People in Varanasi District of Uttar Pradesh. Int.J.Curr.Microbiol.App.Sci. 9(04): 1169-1174. doi: https://doi.org/10.20546/ijcmas.2020.904.138 